\title{
The quality of public transport: relative importance of different performance indicators and their potential to explain modal choice
}

\author{
A. J. M. Seco ${ }^{1} \&$ J. H. G. Gonçalves ${ }^{2}$ \\ ${ }^{1}$ Civil Engineering Department, \\ Faculty of Science and Technology of University of Coimbra, Portugal \\ ${ }^{2}$ Civil Engineering Department, University of Beira Interior, Portugal
}

\begin{abstract}
This paper aims to present the state-of-the-art in terms of performance indicators for quality evaluation of public transport services in urban areas.

Attending to the problems faced by citizens of major urban areas all over the world, arguments are presented to justify not only the need for development of alternative transports systems relatively to private cars, but also to enhance their use. Through a revision of commonly world-wide performance indicators used in service quality evaluation studies, the paper presents those that reveal a higher potential for fast and reliable representation of citizens service quality evaluation to be used by operators, local authorities or planners. The text finishes with the proposal of future research with the integration of the selected indicators in mode choice models.
\end{abstract}

Keywords: public transport, quality evaluation, performance indicators, mode choice modelling.

\section{The importance of public collective transport system's quality evaluation}

The urban areas in developed and industrialized countries lodge more than $2 / 3$ of their population [19]. Thus, urban problems: economic development, sustainable environment, citizens' security, public health or cultural differences; affect directly and indirectly most of the population, showing that their resolution is of capital importance for each country's vitality, prosperity and economic 
competitiveness. The great physical separation of different economic and ethnic groups of citizens, between central areas and suburbs or between different urban zones, represents an obstacle to the resolution of social and economical problems. The majority of the present urban transport systems contribute to enhance these problems, stimulating the use of private cars in detriment of more sustainable modes. Contrasting with what happens in villages and towns, in many cities the majority of the citizens' destinations cannot be found in a convenient walking distance. This problem can only be solved implementing global transport systems that promote the accessibility/mobility of all citizens. This accessibility/mobility must be understood as the possibility for any citizen, goods or information with a specific trip purpose to reach any activity, business or land use, in convenient conditions. High quality public collective transport systems generally contribute for the appearance of mixed land uses - for example, residential with shopping or offices and shopping - stimulating central urban districts of great activity and more diversified residential developments. Excluding private car trips of construction and maintenance costs related to road infrastructures (bridges, urban streets, road pavements, signalling, etc.), of environmental impacts, or the effects in national energy dependence, leads to the illusion that private car is always cheaper, stimulating its use in detriment of other socially and environmentally more sustainable modes. It also tends to underestimate the economical value of suburban areas compared to the more central ones. While certain land uses, as industrial or leisure, have greater viability in low density areas, others have their viability optimised in high density areas, such as business, institutional and financial services, cultural or educational establishments, and cultural or sport events. To allow the coexistence of all these activities in a city area, which are essential for its vitality, the urban transport systems must serve efficiently a great variety of land use densities and traffic flows. This effectiveness can only be achieved through collective public transport systems that present themselves as a feasible alternative to private car. Its mission is so strictly connected to the citizens' quality of life and the cities' economic development, that their development cannot be guided solely by market forces.

\section{Characterization of urban public transport systems}

The public transports systems have complex characteristics that difficult a concrete definition of their quality. They are characterized by: supplying daily services to all the citizens in large areas; they are organized with several infrastructure that interconnect them with other transport modes, like streets, sidewalks or parking lots; they carry not only people but also/or goods; the information and ticketing systems are also an essential part of the service; and the citizens expect services without failures, that takes them to their destination, on time and in an organized way.

Other inherent specificities of the delivered service that make improvements more complex are: the intangibility of some of its "production" (namely the staff's attitude regarding passengers); the partaking of other service's users in the 
production process (the service cannot be delivered if the customers don't show up, and their attitudes influences the service quality delivered to other users); the degree of simultaneously between production and consumption of their service (transport units) and the offer of a perishable service (a empty seat in a trip cannot be kept and sold in the following day).

The service quality is thus one of the key-point in the provision of urban public transports, thus one that must be taken in consideration, not only by the municipal authorities, but also by the service providers.

Considering the competition of the private car, the public transport sector has to improve continuously its quality and to modify the services that it offers in order to recover passengers. Unfortunately the day-to-day experience shows that much still continues undone. The majority of the services are characterized by: the reliability of their transports that, in general, could be improved; the passenger's assistance in service failure cases that tends to be unsystematic and somehow amateur; the wait and trip times, as well as the transfers times, between urban transports and also among others transport modes, that could be easier and faster; and the fact that they continue to fail in offering a global mobility solution that many citizens expect and consider essential, in their daily options.

A critical step in the improvement of any service consists of reaching a realistic evaluation of the delivered service quality level, allied with a clear knowledge of the public satisfaction and expectations. Future improvements must be perceivable for all users, present and potential ones, and conveniently publicized, and must be radical enough to overcome the natural inertia to modify mode choice habits and convincing enough to encourage citizens to travel by urban public transports.

\section{Quality evaluation}

Just 25 years ago service quality was not a relevant issue for the transport sector. Only in the end of the 80 's, beginning of the 90 's, did it started to gain greater relevance, existing several reasons, different in each country, which led to its development. The reduction of the public transport subsidies allied to the necessity to increase the productive efficiency, and the increasing introduction of competition through payment in function of the service quality satisfaction rate (at least in some countries), were between the most important causes [13].

The fact that service quality importance was recognized, did not lead to great advances in this field. In the majority of the countries there exists a lack in a uniform evaluation approach and the quality concept continues somehow unclear and theoretical.

Considering the international references consulted about public collective transport systems quality evaluation $[2,8,10,12,13,15]$ the most significant vectors of intervention can be summarized in the Quality Circuit presented in figure 1 .

According to Project QUATTRO [13] the quality circuit includes the Expected Quality $\left(\mathrm{Q}_{\mathrm{e}}\right)$ considering it as the level of quality anticipated/requested by customers, defined in terms of implicit and explicit expectations. The level of 
expected quality by a passenger can be defined as the sum of a certain number of quality issues, duly weighed. The Targeted Quality $\left(\mathrm{Q}_{\mathrm{t}}\right)$ is the quality level that the operator intends to provide. It depends of the perception level of expected quality, internal and external pressures, budget restrictions and the operator performance. The Delivered Quality $\left(\mathrm{Q}_{\mathrm{d}}\right)$ is the quality level reached in a daily base, under normal operation conditions. Service ruptures, from operator fault or not, are taken into account. The Perceived Quality $\left(\mathrm{Q}_{\mathrm{p}}\right)$ is the quality level that passengers perceive on their daily trips.

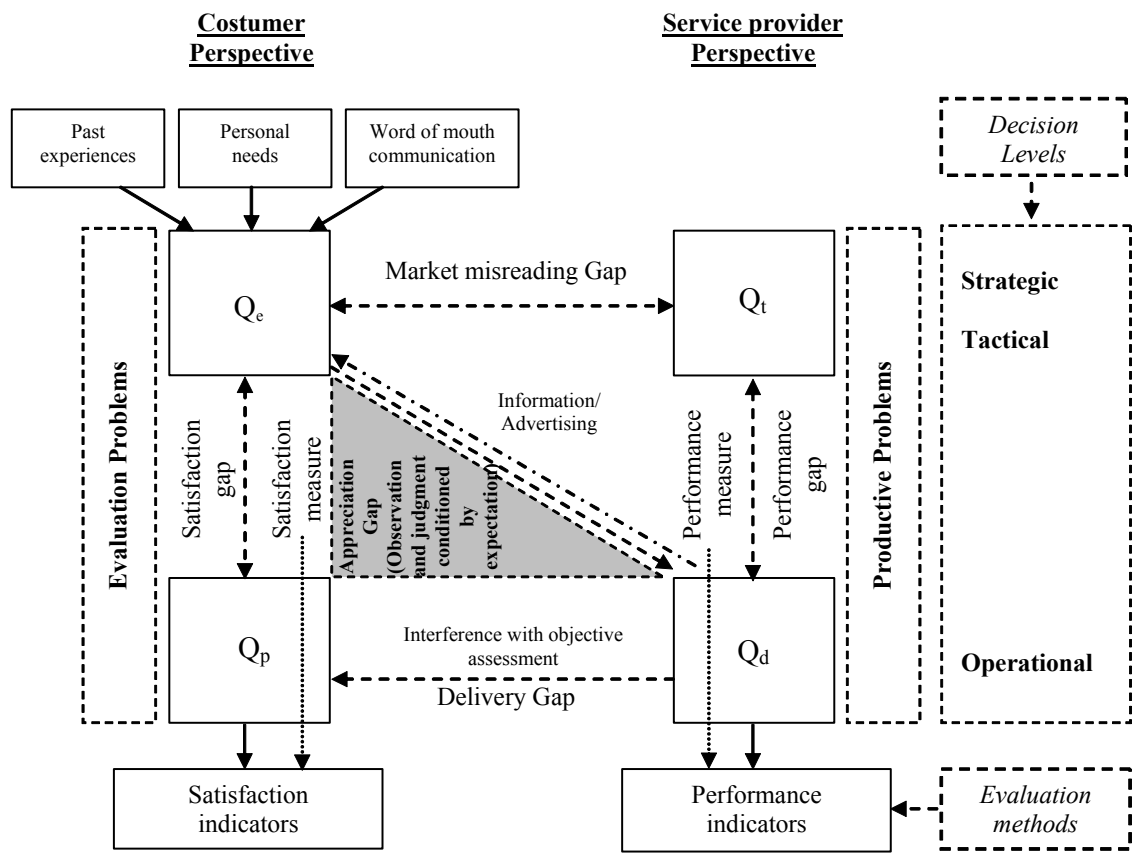

Figure 1: $\quad$ Public transport service quality circuit and its specificities (based on $[10,12,13,15])$.

In 1999, the TRB [15] presented the discrepancies between the different evaluation vectors for the different service qualities. These gaps were related to problems such as the discrepancies between the operators' executives' perception and the consumers expectations, that lead to mistakes about which performance indicators are more important in passengers service qualification, which features must be considered in order to meet passenger's needs and what levels of performance are needed to deliver a high quality service. Other gaps presented referred to the existence of constrains (resources or market conditions) which prevent management from delivering what passengers expect, or absence of management commitment to deliver a quality service. Another discrepancy referred relates to the difficulties in standardizing employee's performance, even when good practice rules exist. It also states the need for correct and reliable 
media advertising and other relevant operational information communication that can affect the consumer's expectations. The promise of a service quality that is not possible to deliver raises the initial expectations but also diminishes the quality perception when the promises are not fulfilled. Furthermore, the operators should not neglect to inform consumers of the special efforts made to assure a higher service quality, specially the ones not visible on daily trips, which could affect their perception of the delivered service. Finally it states that the service quality that a consumer perceives is a function of the magnitude and direction of the existing gap between the expected service and the perceived one. The magnitude and direction of this gap depend on the nature of the gaps associated with the design, marketing and the service delivery.

Macário [10] includes the decision levels which should be considered in any quality assessment.

The strategic decision level is related with the long term decision, namely defining mobility policy, market shares to be reached, the level of systems' financial sustainability, their intervention areas, the levels of accessibility intended for different areas at different times, delimiting the public service character to be provided and the means to be allocated to provide those services, or establishing the degree of intermodality to be provided by the system.

The tactical level focus on medium term decisions basically related to the configuration of the system supply, individual service definition in order to satisfy the different market segments, more detailed specifications such as the type of vehicles, routes, timetables, variety of fares, additional services, definition of performance standards or definition of contractual basis for engagement of service providers.

The operational level concerns are mostly short term ones and related to management of services and resources. This is the action level where the service effectively is carried out but also where the performance monitoring is undertaken. Production scheduling can extend from infrastructure management until vehicles and staff rostering. Depending on the integration level of these activities, these can be allocated to one or several entities, depending on the regulatory framework.

Summarising, it seems clear that the delivered and perceived qualities (operational level of decision), are the most interesting ones to assess the influence that public transports can have in daily modal choices of urban citizens.

\section{Performance indicators}

\subsection{Introduction}

The variety of performance indicators pointed out in international references, discloses that there still doesn't exist a consensus for a uniform and universal methodology for urban public transport systems' quality evaluation. One of the problems mentioned is the wide influence that transport systems have on the environment, on society, on urban land use, on economic development, among others. 
The methodologies suggested in international references [8, 13, 15] for service quality surveys recommend the implementation of regular/periodic inquiries where customers are questioned on their degree of satisfaction on certain evaluation parameters, translated by performance indicators. The methodologies differ in the way these inquiries are done but generally they use objective indicators, and recommend different statistical methods for the data processing. In this data processing special attention is recommended in the definition of the real importance of each indicator and its relative importance regarding all the other. There are also suggested methodologies to evaluate the results' accuracy.

The performance indicators can be computed directly or can result from the ratio between two or three variables, and can be quantitative or qualitative. They can represent the impact at individual choices, at the community level, or on the accomplishment of national goals. They can also be more focussed on comparing the system's effectiveness regarding other services or on evaluating its efficiency.

Giannopoulos [5] and Meyer and Miller [11] present as essential criteria for the performance indicator selection the following features:

- Consistency with the goals: The performance indicators must allow the measurement of the service impacts in certain pretended goals, such as the reduction of the atmospheric pollution, of road congestions, of social mobility equity, of private car dependence reduction, among others;

- Concise and appropriate to the intended detail level: when selecting indicators special care should be taken to prevent data redundancy and duplication. Thus, although many times neglected, the essential data definition phase and the way it will be processed must gain significance justifying bigger financial and time investments, allowing future work and investment savings. The desired appropriate detail level must also be evaluated.

- Availability: The essential information for the indicators estimation must be easily obtainable and preferably be pre-existing;

- Necessary acquisition time and financial resources: The time and costs for essential data acquisition for indicators' quantification must be taken into account in its selection;

- Measurability: The indicators should be relatively simple to quantify, implying some difficulties when using qualitative indicators (for example, the employees' politeness can be very important for customers but its effective and objective quantification is extremely complicated);

- Minimization of uncontrollable factors: The selection of performance indicators must minimize the use of indicators co-related with factors that the operators cannot control, such as road congestions or road network definition;

- Robustness: They must allow their use in different scenarios and through times.

- Clearness/Comprehensibility: The indicators influence must be easily understood by politicians and planners;

- Sensitivity and reciprocity: It indicates the minimum level of variation in urban systems that the indicators must detect; 
- Isolation of influences: They must allow the perception of each individual indicator influence on the urban system;

The conjugation of all these conditions limits the range of usable indicators. The selection of the indicators with higher potential must be done evaluating which set better satisfy the presented checklist.

In addition to the specified criteria, there are others that also need attention. Bad institutional organization and commercial competition between private operators raise serious problems to the independent researchers that try to study these interactions. The most common problems relate with the willingness of private operators in giving access to non-favourable information (for example related to punctuality) or about their revenues/profits. The lack of strategic vision of many managers, either from operators or public entities, that don't encourage data acquisition and recording across time and its availability to other institutions at acceptable costs, is another fact that raises the difficulties in service quality studies, mainly in urban areas where several small operators compete between themselves for the concession of the most lucrative routes.

\subsection{The variety of performance indicators}

Taking into account 12 North American, Australian and European references [1, $4,5,7-10,12-14,16,18]$ it could be verified the great variety of performance indicators which are generally used. The average number of indicators suggested per reference is 16 , varying between a minimum of 8 and a maximum of 33. An effort to synthesise the variety of presented indicators, grouped by similarity, allowed summarizing them in a set of 49 more common. From the analysis only 10 indicators $(20 \%)$ are used in more than $50 \%$ of the 12 references. The most common indicators are:

- Reliability/Punctuality (100\%), pointed by all studies as the most important factor regarding to customers. Only reliable/punctual services can allow the citizens daily trips' organization and stimulate the use/dependence on public transports. It can be computed by the following equation:

$$
\mathrm{P}=\frac{\sum \mathrm{PT}_{ \pm 5 \mathrm{~min}}}{\sum \mathrm{PT}}
$$

where $\mathrm{P}$ is the punctuality em $\%, \Sigma \mathrm{PT}_{ \pm 5 \min }$. is the number of public transports that arrive between 0 and 5 minutes either before (worst case) or after the scheduled time, and $\sum \mathrm{TP}$ are all the public transport arriving [5];

- Commercial speed/Trip time (92\%), although directly related, the trip time is of easier perception by customers. It takes into account all time spent on trip, including stopped time. In a very simple way it can be calculated by the equation:

$$
\mathrm{V}_{\mathrm{c}}=\frac{\mathrm{L}}{\mathrm{T}}
$$


where $\mathrm{V}_{\mathrm{c}}$ is the commercial speed $(\mathrm{km} / \mathrm{h})$, $\mathrm{L}$ is the route length $(\mathrm{km})$ and $\mathrm{T}$ it total travel time from origin to destination (in hours). Tyler [17] still refers other formulations that take into consideration the number of stops per kilometre, the driver's behaviour, the distance between stops and/or the stationary time at each stop;

- Comfort on the run $(92 \%)$, includes the travel smoothness on the start and braking, and the drivers' attention with passengers entering and seating or leaving, and the availability of free seats. Bus occupancy can be a proxy to evaluate the trip comfort, calculated as [5]:

$$
\mathrm{O}=\frac{\mathrm{P}}{\mathrm{S}}
$$

where $\mathrm{O}$ is the occupancy rate $(\%), \mathrm{P}$ is the total number of passengers present at a given time or part of the network, and $\mathrm{S}$ is the number of seats available; - Service frequency/Regularity (75\%), the number of hourly departures, or the time between successive transport units. It can be calculated by the equation:

$$
\mathrm{F}=\frac{\mathrm{N}_{\mathrm{d}}}{\mathrm{T}}
$$

where $\mathrm{F}$ is the frequency $\left(\mathrm{PT}_{\text {units }} / \mathrm{h}\right), \mathrm{N}_{\mathrm{d}}$ is de number of public transport units departures during a $\mathrm{T}$ period of time (in hours). The inverse of frequency gives the average time between departures or the regularity of the public transport units;

- Cleanness and maintenance (75\%), of the vehicles and supporting infrastructures (toilets and bus stops/terminals);

- Safety (67\%), despite an unclear perception by passengers on their daily trips it has an psychological effect and the perception of the operators' concern with passengers safety increases their confidence on the service and on the operator's commitment in delivering a good service. Generally it can be expressed by the total number of accidents (Acc) involving humans and property per 100000 vehicles-kilometres run (5) or the number of accidents involving passengers per million of passengers carried (6) [5]:

$$
\mathrm{S}_{\mathrm{f}}=\frac{\text { Acc }}{100000(\text { vehicle }-\mathrm{km})}
$$

or

$$
\mathrm{S}_{\mathrm{f}}=\frac{\text { Acc }}{1000000 \text { (passengers })}
$$


- Trip price/Fare level (58\%), including the ticket price, the eventual parking at interfaces, and in some studies the ratio between public transport trip costs and total private car trip cost. Considering only the most perceivable costs that could affect modal choice, the out of the pocket money, a relative fare level could be computed in the following way:

$$
\mathrm{F}=\frac{\mathrm{C}_{\mathrm{Po}}+\mathrm{C}_{\mathrm{T}}}{\mathrm{C}_{\mathrm{F}}+\mathrm{C}_{\mathrm{Pd}}+\mathrm{C}_{\mathrm{Tl}}}
$$

where $\mathrm{F}$ is the relative far level (\%), $\mathrm{C}_{\mathrm{P}_{0}}$ is the parking cost close to the origin (generally lower), $\mathrm{C}_{\mathrm{Pd}}$ is the parking cost near destination, $\mathrm{C}_{\mathrm{T}}$ is the public transport ticket cost, $\mathrm{C}_{\mathrm{F}}$ is the fuel cost of the private car trip and $\mathrm{C}_{\mathrm{Tl}}$ are eventual toll costs;

- Security (58\%), more perceivable to passengers and with greater impact on their evaluation then safety, generally refers to the felling of security inside the vehicle, during the trip and at bus stops and terminals. It can be evaluated attending to the number of crimes against passengers, staff or public transport property, or by the operator's efforts to assure security, like the presence of Police Officers on board or specified safety devices like security cameras, intercom systems or emergency alarms. One security indicator can be crime rate on the system [16]:

$$
\mathrm{C}_{\mathrm{R}}=\frac{\mathrm{N}_{\mathrm{C}}}{100000 \text { trips }}
$$

where $C_{R}$ is the annual crime rate and $\mathrm{N}_{C}$ is the number of annual reported crimes all over the system;

- Trip environment (58\%), considering inside temperature, the occupancy rate and the behaviour of other passengers;

- Transfers necessity (50\%), incorporating comfort in transfers, their number, modal integration, and waiting time during transfers. Usually passengers tend to prefer one-seat ride from origin to destination, but one way of evaluation a public transport system considering this indicator can be the percentage of trips requiring transfers [16]:

$$
\mathrm{T}_{\mathrm{f}}=\frac{\mathrm{J}_{\mathrm{T}}}{\sum \mathrm{J}}
$$

where $T_{f}$ is the percentage of trips requiring transfers, $J_{T}$ are the number of journeys that need transfers and $\Sigma \mathrm{J}$ are all the journeys made by public transport;

- Customers contact (50\%), employee's politeness, specially the drivers, promptness to solve problems and to give information, existence of an information and complaining office. 
Considering the conditions mentioned in point 4.1, although some can be computed indirectly (as the trip environment that can be relatively evaluated by the existence of air conditioned), performance indicators like comfort on the run, trip environment, cleanness and maintenance or costumers contact, are predominantly qualitative ones and therefore harder to evaluate externally.

\subsection{Most valued indicators}

The fact that the indicators referred in the previous point are the most common in the consulted references does not guarantee, however, that they are the most important ones for the citizens who already use, or can use in the future, public transports. A service can present an acceptable average service level, but the evaluation that is done by its passengers is based mainly on the parameters that in their point of view are more important. Thus, it is necessary to evaluate which indicators are more important when citizens make their decisions about what transport mode to use. From the consulted references, 5 presented studies on the importance (relative or absolute) of some indicators [4, 8, 12, 14 and 15]. Hence, it was possible to reduce the set of most common indicators to a group of 19 , pointed as most important for public collective transports passengers' (bus and train). From this group only $5(26 \%)$ are referred in at least $50 \%$ of the studies:

- Reliability/Punctuality (100\%);

- Regularity/Frequency (80\%);

- Operational speed / Trip time (60\%);

- Trip cost $(60 \%)$;

- Vehicle/System cleanness (60\%);

From the most valued indicators listed, the ones that present greater potential for a quick service quality evaluation are: reliability/punctuality (with operators cooperation); regularity/frequency (through the available timetables); operational speed/trip time (usually it is easier to obtain commercial speed using the available routes definition from regulating authorities and publicly available timetables, adding wait times at bus stops and delay dued to traffic congestions); and trip price (eventually correlated with the total cost estimation of the same trip by private car). The indicator cleanness due to difficulties for an objective quantification makes it use more complex.

\subsection{Typical values for urban public transport performance indicators}

The typical values for performance indicators referred in the international references can be consulted in table 1 .

Relatively to trip costs, the variety of realities in different cities does not allow the presentation of reference values. However, project COST [3] relates that: 
- A reduction in public collective transport fares of $30 \%$ would decrease car share only by $2 \%$;

- Parking costs equal to fares for public transports would decrease private car mode share by $8 \%$;

- Increases in parking costs of $30 \%$ results in a decrease of car share of $8 \%$ to $10 \%$;

- Doubling parking costs would lead to a decrease of car share of $21 \%$.

The performance indicator Vehicle/system cleanness is of subjective nature making it hard to present reference values.

Table 1: Common values for the performance indicators with higher potential for passengers' quality evaluation $\left({ }^{1}-[18] ;^{2}-[5] ;^{3}-[6]\right)$.

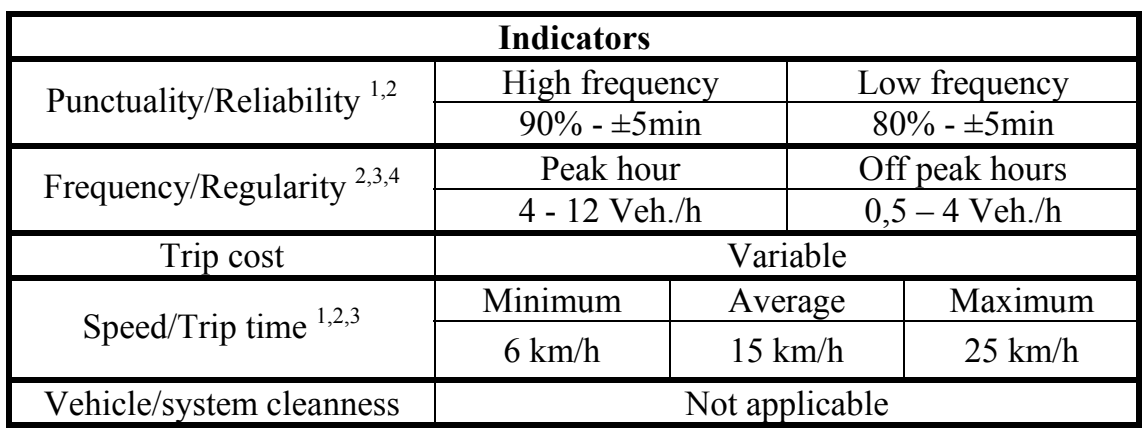

\section{Synthesis}

From what was referred, it seems clear that the mitigation of great part of the problems faced currently by citizens of the majority of great world-wide cities passes by offering viable mobility alternatives to allow a reduction on private car dependence. Hence, this communication presented a performance indicators review showing the ones with better conditions to translate the way citizens apprehend the quality of the available public collective transports services. From the variety of indicators presented by some international references, it was evident the lack in consensus for a quality evaluation methodology. However, it was possible to verify that a restricted group of indicators is common to the majority of the consulted studies, and of these, the ones that present greater potential to assess the way quality is apprehended by the citizens. A group of 5 performance indicators was identified as the best to infer service quality, but the quantification of some still raises some questions that need further studies. Bearing in mind the most common values of the selected indicators, future work developments will focus on more studies for their incorporation in modal choice modelling, which beside the typical social-economic indicators should also include indicators related to restrictions for free private car usage. 


\section{References}

[1] Beirão, G. \& Cabral, J., Modelling service quality for public transport contracts: Assessing user's perceptions. $9^{\text {th }}$ Thredbo - Conference on Competition and ownership in land transport, Instituto Superior Técnico, Lisboa, 2005.

[2] Bunting, M., Making public transport work. McGill-Queen's University Press, 2004.

[3] COST342, Parking policies and the effects on economy and mobility. COST Action 342, Technical Committee on Transport, CROW, August, 2005.

[4] DTSF, 1999 Transit Customer Satisfaction Index - Final Report: Results of Survey and conclusions. Department of Transportation State of Florida, October, 2000.

[5] Giannopoulos, G., Bus planning and operation in urban areas: a practical guide. Avbury, Hampshire, 1990.

[6] Gonçalves, J., Os índices de oferta de estacionamento como instrumentos de políticas e gestão de mobilidade. MSc Thesis in Urban Engineering, FCTUC, December, Coimbra (in portuguese), 2002.

[7] Grava, S., Urban transportation systems: Choices for communities. MacGraw-Hill, New York, 2003.

[8] Hensher, D.; Stopher, P., \& Bullock, P., Service quality - developing a service quality index in the provision of commercial bus contracts. Transportation Research - Part A, Pergamon -Elsevier Science, v.37, p. 499-517, 2003.

[9] Lyons, G.; Marsden, G.; Beecroft, M. \& Chatterjee, K., Transport Visions: Transport requirements. Transportation Research Group, University of Southampton, Number 2, Landor Publishing, 2001.

[10] Macário, R., Quality management in urban mobility systems: an integrated approach. $\mathrm{PhD}$ Thesis in Transport, Instituto Superior Técnico, Universidade Técnica de Lisboa, November, Lisboa, 2005.

[11] Meyer, M \& Miller, E., Urban transportation planning (2 ${ }^{\text {nd }}$ Ed.). McGraw-Hill, New York, 2001.

[12] MOTIF, Market Orientated Transport in Focus: Final report for publication. European Commission under the Transport RTD Programme of de EU's $4^{\text {th }}$ Framework for Research, Technological Development and Demonstration, 2000.

[13] QUATTRO, Quality approach in tendering urban public transport operations - Final Report - Synthesis and Recommendations. European Commission under the Transport RTD Programme of de EU's $4^{\text {th }}$ Framework for Research, Technological Development and Demonstration, 1998.

[14] Swanson, J.; Ampt, L. \& Jones, P., Measuring bus passenger preferences. Traffic Engineering and Control, v.38, Nº, p. 330-336, 1997.

[15] TRB, TCRP Report 47 - A Handbook for Measuring Customer Satisfaction and Service Quality. Transit Cooperative Research Program - 
Urban Transport XIII: Urban Transport and the Environment in the 21st Century 325

Transportation Research Board - National Academy Press, Washington, 1999.

[16] TRB, TCRP Report 88 - A guidebook for developing a transit performance-measurement system. Transit Cooperative Research Program - Transportation Research Board - National Academy Press, Washington, 2003.

[17] Tyler, N., Accessibility and the bus system: from concepts to practice, Thomas Telford, London, 2002.

[18] Vuchic, V., Urban Public Transportation - Systems and Technology. Prentice-Hall, Inc., New Jersey, 1981.

[19] Vuchic, V., Transportation for Liveable Cities. Center for Urban Policy Research - Rutgers, State University of New Jersey, New Jersey, 1999. 